\title{
Load frequency control of interconnected hydro-thermal power system using conventional pi and fuzzy logic controller
}

\author{
Muhammad Ahsan Zamee ${ }^{1}$, Dipankar Mitra ${ }^{2}$, Sadaf Yusuf Tahhan ${ }^{2}$ \\ ${ }^{1}$ Department of Electrical \& Electronic Engineering, World University of Bangladesh, Dhaka, Bangladesh \\ ${ }^{2}$ Department of Electrical \& Electronic Engineering, Chittagong University of Engineering and Technology, Chittagong, Bangladesh
}

\section{Email address:}

zamee_mist@yahoo.com (M. A. Zamee),dipankar.mitra.dipu@gmail.com (D. Mitra), tahhansadaf@gmail.com (S. Y. Tahhan).

\section{To cite this article:}

Muhammad Ahsan Zamee, Dipankar Mitra, Sadaf Yusuf Tahhan. Load Frequency Control of Interconnected Hydro-Thermal Power System Using Conventional PI and Fuzzy Logic Controller. International Journal of Energy and Power Engineering.

Vol. 2, No. 5, 2013, pp. 191-196. doi: 10.11648/j.ijepe.20130205.12

\begin{abstract}
In industry or any area increasing load is a vast problem for power generation plants due to increase in demand for power. So making balance between generation and demand is the operating principle of load frequency control (LFC). The reliable operation of a large interconnected power system necessarily requires an Automatic Generation Control (AGC). The objective of AGC is to regulate the power output of Generators within a specified area in response to change in the system frequency, tie line power or relation of the two to each other, so as to maintain the scheduled system frequency and power interchange in the other are within the prescribed limits. This paper presents the use of conventional PI controller and artificial intelligence to study the load frequency control of interconnected power system. In the proposed scheme, a control methodology is developed using conventional PI controller and Fuzzy Logic controller (FLC) for interconnected hydro-thermal power system. The control strategies guarantees that the steady state error of frequencies and inadvertent interchange of tie-lines power are maintained in a given tolerance limitations. The performances of the controllers are simulated using MATLAB/SIMULINK package. A comparison of Fuzzy controller and PI controller based approaches shows the superiority of proposed Fuzzy logic controller for step change in loading conditions. The simulation results also tabulated as a comparative performance in view of settling time and peak over shoot.
\end{abstract}

Keywords: Load Frequency Control, Fuzzy Logic Controller, PI controller, MATLAB/SIMULINK

\section{Introduction}

Due to increase in system load; turbine speed drops before the governor can adjust the input. As the change in the value of speed decreases, the error signal becomes smaller and the positions of governor valve get close to the required position, to maintain the constant speed. However the constant speed will not be the set point and there will be an offset, to overcome this problem an integrator is added, which will automatically adjust the generation to restore the frequency to its nominal value. This scheme is called automatic generation control (AGC). The role of AGC is to divide the loads among the system, station and generator to achieve maximum economy and accurate control of the scheduled interchanges of tie-line power while maintaining a reasonability uniform frequency. Automatic generation control (AGC) plays a very important role in power system as its main role is to maintain the system frequency and tie line flow at their scheduled values during normal operating period. Automatic generation control with primary speed control action, a change in system load will result in a steady state frequency deviation, depending upon governor droop characteristics and frequency sensitivity of the load. Restoration of the system frequency to nominal value requires supplementary control action which adjusts the load reference set point. Therefore the primary objectives of the automatic generation control are to regulate frequency to the nominal value and to maintain the interchange power between control areas at the scheduled values by adjusting the output of selected generators. This function is commonly referred to as load frequency control. A secondary objective is to distribute the required change in generation among the units to minimize the operating costs. A control signal made up of tie line flow deviation added to frequency deviation weighted by a bias factor 
would accomplish the desired objective. This control signal is known as area control error (ACE).ACE serves to indicate when total generation must be raised or lowered in a control area. In an interconnection, there are many control areas, each of which performs its AGC with the objective of maintaining the magnitude of ACE (area Control Error) "sufficiently close to 0 " using various criteria. In order to maintain the frequency sufficiently close to its synchronous value over the entire interconnection, the coordination of the control areas' actions is required. Any wide deviation from the nominal value of frequency or voltage will lead the system to total collapse. Hence AGC has gained importance with the growth of interconnected systems and with rise in size of interconnected system automation of the control system have aroused. A number of control strategies exist to achieve better performance. [7]

The most applied controller is Conventional Proportional Integral (PI) [3, 6]. It is easier but usually gives large settling time. Most research going on now is based on artificial intelligent systems (fuzzy and neural networks). The inherent gain of these techniques is that they do not require the system model and identification but depend on human expertise knowledge of the behavior.

In this paper, a fuzzy logic controller along with PI controller is proposed and performance comparison is carried out for conventional PI.

\section{Load Frequency Control Theory}

\subsection{The Investigated Power System}

The detailed block diagram modeling of two area thermal-hydro power system for load frequency control investigated is shown in figure 1. An extended power system can be divided into a number of load frequency control areas interconnected by means of tie lines. Without loss of generality one can consider a two- area case connected by single tie line (Surya-Prakash et al.2009).

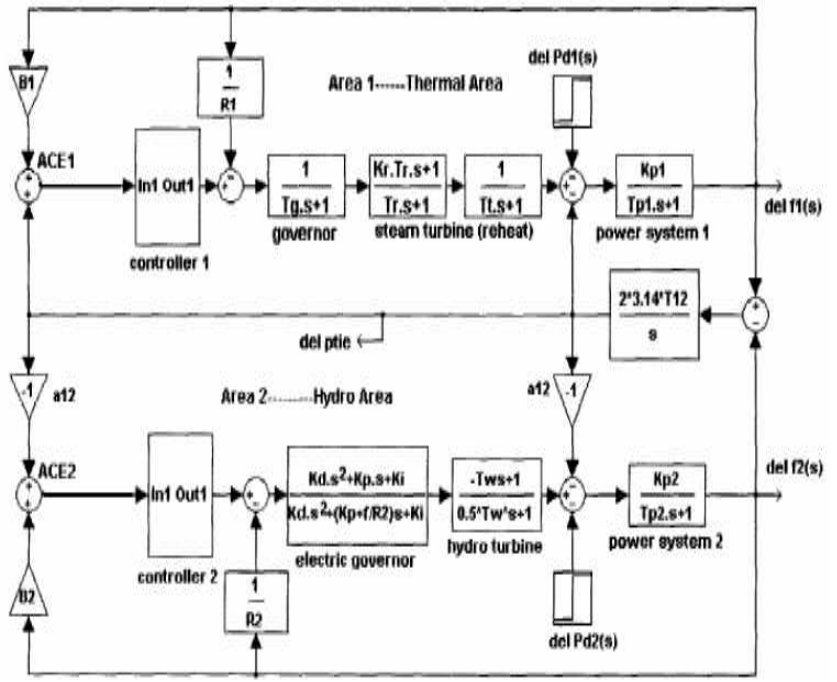

Fig. 1: Block diagram model of hydro-thermal reheat power system.
The control objectives are as follows:

- Each control area as for as possible should supply its own load demand and power transfer through tie line should be on mutual agreement.

- Both control areas should controllable to the frequency control.

In an isolated control area case the incremental power $(\triangle P G-\triangle P D)$ was accounted for by the rate of increase of stored kinetic energy and increase in area load caused by increase in frequency. Since a tie line transports power in or out of an area, this fact must be accounted for in the incremental power balance equation of each area.

\subsection{Modeling of the Tie-Line}

The power transfer equation through tie line is given by,

$$
P_{12}=\frac{\left|V_{1}\right|\left|V_{2}\right|}{x} \operatorname{Sin}\left(\delta_{1}-\delta_{2}\right)
$$

$P_{12}=$ Power transferred from area 1 to 2 through tie line. Considering area 1 has surplus power and transfers to area 2.

$$
P_{12}=\frac{\left|V_{1}\right|\left|V_{2}\right|}{X_{12}} \operatorname{Sin}\left(\delta_{1}-\delta_{2}\right)
$$

Therefore, Power transferred from Area 1 to Area 2 is given by the following equation

$$
\Delta P_{12}(s)=\frac{2 \pi T^{0}}{s}\left(\Delta f_{1}(s)-\Delta f_{2}(s)\right)
$$

$\mathrm{T}^{0}=$ Torque produced

\subsection{Tie line Control}

In normal operation the power on the tie-line follows from the equation

i.e.

$$
\begin{aligned}
& {\left[\Delta P_{T 1}(s)-\Delta P_{E 1}(s)-\Delta P_{12}(s)\right]=\frac{2 H_{1}}{f_{0}} s \Delta f_{1}(s) } \\
+ & B_{1} \Delta f_{1}(s) \\
& =\frac{2 H_{1}}{f_{0}} \Delta f_{1}(s) B_{1}\left[\frac{1}{B_{1}} s+1\right] \\
\text { If } \quad & \frac{2 H_{1} B_{1}}{f_{0}}=\frac{1}{K_{P 1}}
\end{aligned}
$$

Equation (4) can be written as

$$
\Delta f_{1}(s)=G_{P 1}(s)\left[\Delta P_{T 1}(s)-\Delta P_{E 1}(s)-\Delta P_{12}(s)\right]
$$




$$
\begin{aligned}
& G_{P 1}(s)=\frac{K_{P 1}}{1+s T_{P 1}} \\
& \Delta P_{12}=\Delta P_{21}
\end{aligned}
$$

Where $\Delta \mathrm{P}_{\mathrm{E}}$ is real load change

Due to the action of turbine controllers, the generator increases its output by the amount $\Delta \mathrm{P}_{\mathrm{T}}$.

The net surplus power $\Delta \mathrm{P}_{\mathrm{T}}-\Delta \mathrm{P}_{\mathrm{E}}$ will be absorbed by the system.

Tie-line bias control is used to eliminate steady state error in frequency in tie-line power flow. This states that the each control area must contribute their share to frequency control in addition for taking care of their own net interchange.

Let

$\mathrm{ACE} 1=$ area control error of area 1

$\mathrm{ACE} 2=$ Area control error of area 2

In these control areas, $\mathrm{ACE}_{1}$ and $\mathrm{ACE}_{2}$ are made linear combination of frequency and tie line power error.

$$
\begin{gathered}
A C E_{1}=\Delta P_{12}+b_{1} \Delta f_{1} \\
A C E_{2}=\Delta P_{21}+b_{2} \Delta f_{2}
\end{gathered}
$$

Where, the constant $b_{1} \& b_{2}$ are called area frequency bias of area 1 and area 2 respectively.

Now $\triangle \mathrm{PR}_{1}$ and $\triangle \mathrm{PR}_{2}$ are mode integral of $\mathrm{ACE}_{1}$ and $\mathrm{ACE}_{2}$ respectively.

$$
\begin{aligned}
& \Delta P R_{1}=-K_{i 1} \int_{0}^{t}\left(\Delta P_{12}+b_{1} \Delta f_{1}\right) d t \\
& \Delta P R_{2}=-K_{i 2} \int_{0}^{t}\left(\Delta P_{21}+b_{2} \Delta f_{2}\right) d t
\end{aligned}
$$

Taking Laplace transform of the above equation, we get

$$
\begin{aligned}
& \Delta P R_{1}(s)=-\frac{K_{i 1}}{s}\left[\Delta P_{12}(s)+b_{1} \Delta f_{1}(s)\right] \\
& \Delta P R_{2}(s)=-\frac{K_{i 2}}{s}\left[\Delta P_{21}(s)+b_{2} \Delta f_{2}(s)\right]
\end{aligned}
$$

The step changes $\triangle P D 1$ and $\triangle P D 2$ are applied simultaneously in control area 1 and 2 respectively. When steady state conditions are reached, the output signals of all integrating blocks will be constant and their input signal must become zero.

i.e. $\Delta \mathrm{P}_{12}+\mathrm{b}_{1} \Delta \mathrm{f}_{1}=0$ (input of integrating block $\left.-\frac{K_{i 1}}{s}\right)(1$

$\Delta \mathrm{P}_{21}+\mathrm{b}_{2} \Delta \mathrm{f}_{2}=0$ (input of integrating block $\left.-\frac{K_{i 2}}{s}\right)(15)$

$$
\left.\Delta \mathrm{f}_{1}-\Delta \mathrm{f}_{2}=0 \text { (input of integrating block }-\frac{2 \pi T_{12}}{s}\right)
$$

$\Delta \mathrm{P}_{12}=\Delta \mathrm{P}_{\text {tie, } 1}$ and $\Delta \mathrm{P}_{12}=\Delta \mathrm{P}_{\text {tie, },}$

Therefore

$$
\frac{\Delta P_{t i e, 1}}{\Delta P_{t i e, 2}}=-\frac{T_{12}}{T_{21}}=-\frac{1}{a_{12}}=\text { Constant }
$$

Hence $\Delta \mathrm{P}_{\text {tie }, 1}=\Delta \mathrm{P}_{\text {tie }, 2}=0$

$\Delta \mathrm{PR}_{1}=\Delta \mathrm{PR}_{2}$

And $\Delta \mathrm{f}_{1}=\Delta \mathrm{f}_{2}=0$

Thus, under steady condition change in the tie- line power and frequency of each area is zero. This has been achieved by integration of ACEs in the feedback loops of each area (Surya-Prakash et al. 2009). Control methodology used (FLC \& PI) is mentioned in next preceding sections. [1, 2, 8]

\section{Controller Used}

a) Conventional PI Controller

b) Fuzzy Logic Controller.

\subsection{Conventional PI Controller}

When an integral controller is added to each area of the uncontrolled plant in forward path the steady state error in the frequency becomes zero. The task of load frequency controller is to generate a control signal $u$ that maintains system frequency and tie-line interchange power at predetermined values [2]. The block diagram of PI controller is shown in figure 2 .

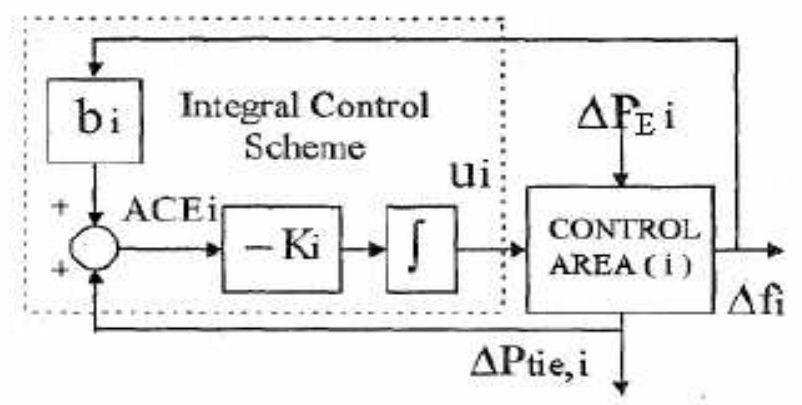

Fig. 2: Conventional PI controller

Conventional Proportional plus Integral controller (PI) provides zero steady state frequency deviation, but it exhibits poor dynamic performance (such as number of oscillation and more settling time), especially in the presence of parameters variation and nonlinearity [10].In PI Controller Proportionality constant provides simplicity, reliability, directness etc. The disadvantage of offset in it is eliminated by integration but this system will have some oscillatory offset. The control signals can be written as:

$\mathrm{U} 1=\mathrm{K}$ p. ACE $1-\mathrm{K}$ i $\int \mathrm{ACE} d t$

$\mathrm{U} 2=\mathrm{K}$ p. ACE2 $-\mathrm{K}$ i $\int \mathrm{ACE} 2 \mathrm{dt}$

Where $\mathrm{Kp}$ and $\mathrm{Ki}$ are proportional and integral gains, 
respectively. For conventional PI controller, the gain $\mathrm{K} p$ and $\mathrm{K} \mathrm{i}$ has been optimized using integral square error (ISE) criterion. For ISE technique, the objective function used is,

$\mathrm{J}=\int_{0}^{t}\left(\Delta \mathrm{F}_{1}+\Delta F_{2}+\Delta P_{t i e}\right) d t$

Where

$\Delta \mathrm{F}=$ Change in frequency

$\Delta \mathrm{Ptie}=$ Change in tie line power

\subsection{Fuzzy Logic Controller}

Fuzzy logic is a problem-solving control methodology incorporated in control system engineering, to control systems when inputs are either imprecise or the mathematical models are not present at all. There are three principal elements to a fuzzy logic controller

1. Fuzzification module (Fuzzifier)

2. Inference rule engine

3. Defuzzification module (Defuzzifier)

For Load Frequency Control the process operator is assumed to respond to respond to variables error $(e)$ and change of error (ce) (that is frequency deviation and change in frequency deviation). five number of triangular membership function (MFs) which provides better dynamic response with the range on input (error in frequency deviation and change in frequency deviation) i.e. universe of discourse is -0.25 to 0.25 . The numbers of rules are 25 . The dynamic response are obtained and compared to those obtained with conventional integral controllers.

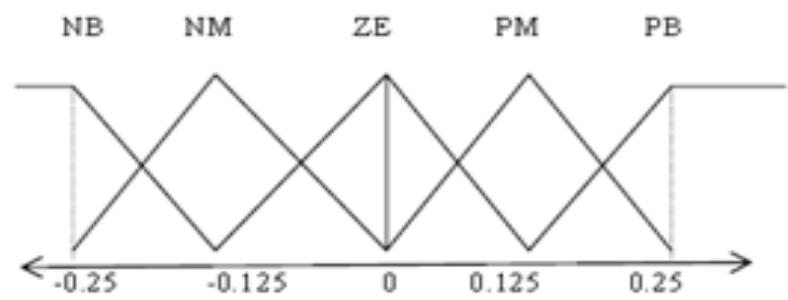

Fig. 3: Membership functions for control input variable

Table 1: Fuzzy Interference rule for fuzzy logic controller

\begin{tabular}{lcccccc}
\hline Input & \multicolumn{5}{c}{$\mathrm{e}(\mathrm{k})$} \\
\hline & & $\mathrm{NB}$ & $\mathrm{NM}$ & $\mathrm{ZE}$ & $\mathrm{PM}$ & $\mathrm{PB}$ \\
$\mathrm{ce}(\mathrm{k})$ & $\mathrm{NB}$ & $\mathrm{NB}$ & $\mathrm{NB}$ & $\mathrm{NM}$ & $\mathrm{NM}$ & $\mathrm{ZE}$ \\
& $\mathrm{NM}$ & $\mathrm{NB}$ & $\mathrm{NB}$ & $\mathrm{NM}$ & $\mathrm{ZE}$ & $\mathrm{ZE}$ \\
& $\mathrm{ZE}$ & $\mathrm{NM}$ & $\mathrm{NM}$ & $\mathrm{ZE}$ & $\mathrm{PM}$ & $\mathrm{PM}$ \\
& $\mathrm{PM}$ & $\mathrm{ZE}$ & $\mathrm{PM}$ & $\mathrm{PM}$ & $\mathrm{PB}$ & $\mathrm{PB}$ \\
& $\mathrm{PB}$ & $\mathrm{ZE}$ & $\mathrm{ZE}$ & $\mathrm{PM}$ & $\mathrm{PB}$ & $\mathrm{PB}$ \\
\hline
\end{tabular}

\section{Results and Discussions}

MATLAB/SIMULINK software has been used for evaluating the performance of proposed controller for both
PI and Fuzzy Logic Controller. For fuzzy logic controller, fuzzy logic toolbox has been used to set up the membership function and interference rules.
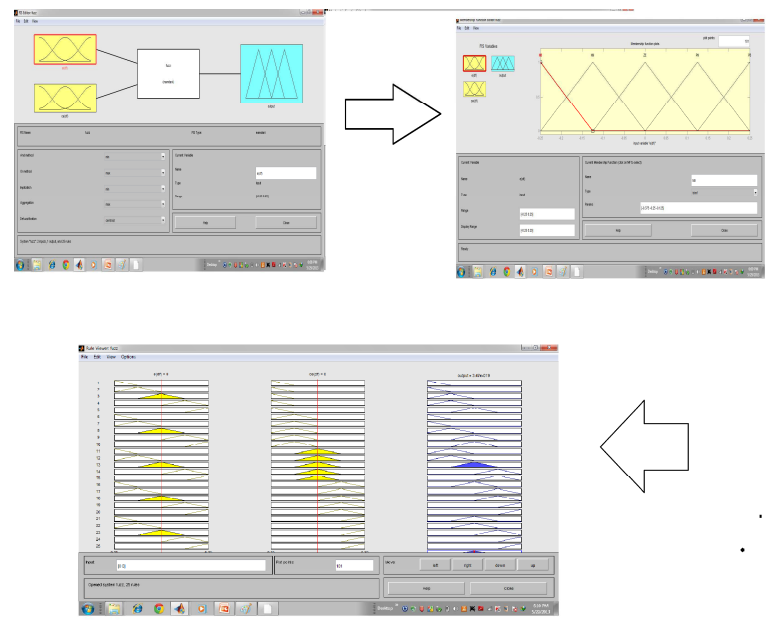

Fig. 4: Setting up fuzzy rules in MATLAB/SIMULINK

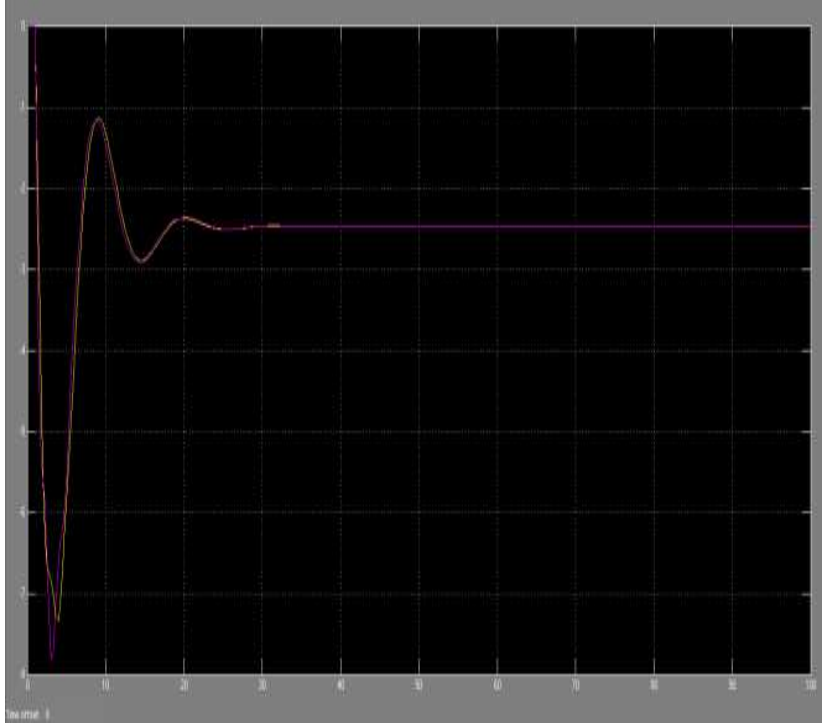

Fig. 5: Frequency response without using any controller.

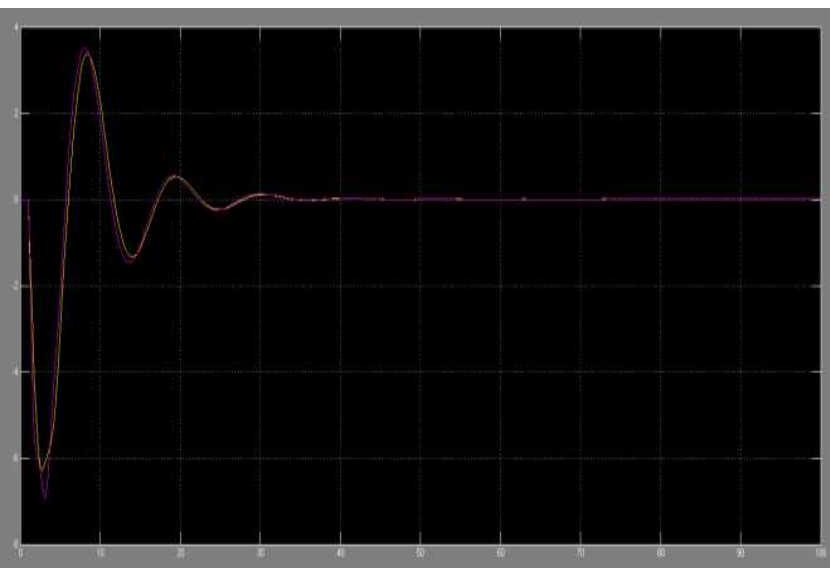

Fig. 6: Frequency Response using PI Controller 


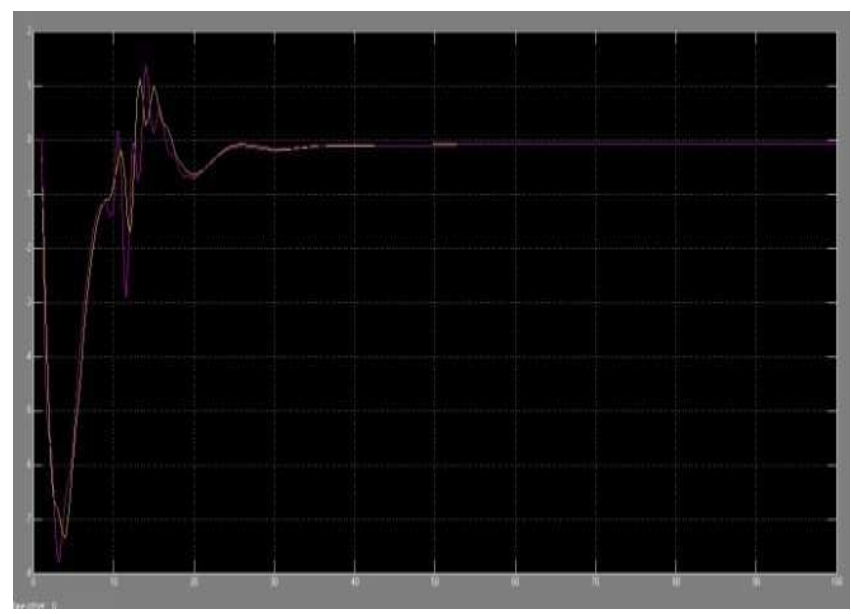

Fig. 7: Frequency response using fuzzy logic controller

\subsection{Comparison of System Performance}

Table 2: Performance evaluation without using any controller

\begin{tabular}{llll}
\hline & Thermal & Hydro & Combined \\
\hline $\begin{array}{l}\text { Frequency } \\
\text { deviation }\end{array}$ & -4 & $-1.5 \sim+2$ & -7.8 \\
Settling time & $\begin{array}{l}\text { Stable at } \\
\text { deviated } \\
\text { frequency }\end{array}$ & $\begin{array}{l}\text { Stable at } \\
\text { deviated } \\
\text { frequency }\end{array}$ & $\begin{array}{l}\text { Stable at } \\
\text { deviated } \\
\text { frequency }\end{array}$ \\
\hline
\end{tabular}

Table3: Performance evaluation using PI controller

\begin{tabular}{llll}
\hline & Thermal & Hydro & Combined \\
\hline $\begin{array}{l}\text { Frequency } \\
\text { deviation }\end{array}$ & $-3.5 \sim+3.5$ & $-4.0 \sim 2.7$ & $-6.5 \sim+2.5$ \\
$\begin{array}{l}\text { Settling time } \\
40 \mathrm{Sec}\end{array}$ & $45 \mathrm{sec}$ & $50 \mathrm{Sec}$ \\
\hline
\end{tabular}

Table 4: Performance evaluation using Fuzzy Logic controller

\begin{tabular}{llll}
\hline & Thermal & Hydro & Combined \\
\hline $\begin{array}{l}\text { Frequency } \\
\text { deviation }\end{array}$ & $-2.5 \sim+3.4$ & $-3.1 \sim 2.5$ & $-7.5 \sim 1.2$ \\
\begin{tabular}{l} 
Settling time \\
\hline
\end{tabular} & 32 & 35 & 38 \\
\hline
\end{tabular}

\section{Conclusion}

From the above research it can be seen concluded that the transient response, settling time and peak overshoot in case of fuzzy logic controller is lesser compared to the conventional PI controller. Thus simulation results of FLC have better control performance over conventional PI when some disturbance in load is given to the system. In short we can say that FLC is adequate for better quality and reliable electric power supply.

\section{Future Scope}

1. More than two areas such as thermal, hydro, gas etc can be interconnected and controlled for automatic generation of controlled power.
2. New controllers can be designed with others Artificial Intelligence algorithms for better control performance in terms of frequency and tie line power deviation.

3. More than one controller can be used such as conventional PI, PID and FLC or Artificial Neural Network in serial or parallel for reducing transient response and peak overshoot.

\section{Appendix}

Parameters are as follows:

$f=50 \mathrm{~Hz}, \mathrm{R} 1=\mathrm{R} 2=2.4 \mathrm{~Hz} /$ per unit $\mathrm{MW}, \mathrm{Tg}=0.08 \mathrm{sec}$,

$\mathrm{Tp}=20 \mathrm{sec}$

$\mathrm{P}$ tie, $\max =200 \mathrm{MW}$

$\operatorname{Tr}=10 \mathrm{sec} \mathrm{kr}=0.5$,

$\mathrm{H} 1=\mathrm{H} 2=5 \mathrm{sec} \operatorname{Pr} 1=\operatorname{Pr} 2=2000 \mathrm{MW}$

$\mathrm{Tt}=0.3 \mathrm{sec} \mathrm{Kp} 1=\mathrm{Kp} 2=120 \mathrm{~Hz} \cdot \mathrm{p} . \mathrm{u} / \mathrm{MW}$

$\mathrm{Kd}=4.0 \mathrm{ki}=5.0 \mathrm{Tw}=1.0 \mathrm{sec}$

$\mathrm{D} 1=\mathrm{D} 2=8.33 * 10-3$ p.u MW/Hz.

\section{Nomenclature}

$F$ : Nominal system frequency

Pri : Area rated power, $H$ i: Inertia constant

$\triangle P D i:$ Incremental load change

$\Delta P g i$ : Incremental generation change

$T 12$ : Synchronizing coefficient, $T \mathrm{~g}$ :Steam governor time constant

$K r$ : Reheat constant, $T r$ : Reheat time constant

$T t:$ Steam turbine time constant

$R i$ : Governor speed regulation parameter

Bi: Frequency bias constant

\section{References}

[1] Anand B., Ebenezer A. Jeyakumar. 2009. Load frequency control with fuzzy logic controller considering non-linearities and boiler dynamics, ICGST-ACSE Journal, ISSN 1687-4811, Volume 8, issue 111, pp 15-20.

[2] Aravindan P., Sanavullah M.Y. 2009. Fuzzy Logic Based Automatic Load Frequency Control of Two Area Power System With GRC, International Journal of Computational Intelligence Research, Volume 5, Number 1. pp. 37-44.

[3] Jawat, T. and Fadel, A, B. “Adaptive Fuzzy Gain Scheduling for Load frequency control", IEEE Trans. on PAS, vol. 14, No 1, February 1999.

[4] Ibraheem, Kumar P., Kothari D.P., 2005. Recent Philosophies of Automatic Generation Control strategies in Power systems, IEEE Transaction on Power System Vol.20, No.1, pp-346-357.

[5] Surya-Prakash, Sinha S.K., Brijesh-Singh, Pandey A.S. 2009. Impact of slider gain on Load Frequency Control using Fuzzy Logic Controller, ARPN Journal of Engineering and Applied Science, Vol. 4, No 7.pp. 20-27.

[6] Edison, B, and Ilie, M, "Advanced Generation control: Technical Enhancements, costs, and Responses of market Driven Demand" Proc. of the 57th Annual American Power 
conf; vol. 57, No. 2, 1995, pp 1419-1427.

[7] Amit Kumar, Aziz Ahmad, Ashwani Grover, Umesh Gupta, "Load Frequency Control Using Fuzzy Logic", International Journal of Scientific and Research Publications, Volume 2, Issue 7, July 2012

[8] Surya Prakash , S. K. Sinha, "Application of artificial intelligence in load frequency control of interconnected power system", International Journal of Engineering, Science and Technology.
[9] A. Mangla and J. Nanda , "Automatic Generation Control of an Interconnected Hydro-Thermal System Using Conventional Integral and Fuzzy Logic controller", International conference on electrical utility, deregulation, destructuring, and power technologies, pp372-377, April 2004.

[10] Q. P. Ha. 1998. "A Fuzzy sliding mode controller", International Conference of Knowledge based Intelligent Electronic System. Adelaide, Australia. 2123 2nd April. 